\title{
PUSTAKAWAN AKADEMIK SEBAGAI MITRA RISET DI PERGURUAN TINGGI
}

\author{
Oleh : Ulpah Andayani
}

\begin{abstract}
This paper deals with the role of academic librarians in higher education program. The focus of the study is to explain the roles of academic librarians as research partner in the higher education programs. Based on the analysis of the literatures, it was found that academic librarians have a strategic role in successing the research program. There are three main roles of academic librarians in the research activities, that are providing information research services, conducting research skills training, and assisting academic members in publishing and disseminating the research findings. Furthermore, the Librarians serve and assist the researchers individually in performing the research activities, as well as arrange and implement programs in groups or classes program in teaching research skills through information literacy program. Through the teaching of information literacy, the academicians are provided the ability to identify the sources of information, the ability to search information, and the ability to manage the citations.
\end{abstract}

Keywords : university library, academic librarian, research consultant, information literacy, scientific publishing

\begin{abstract}
Abstrak
Tulisam ini berkaitan dengan peran pustakawan akademik sebagai mitra atau partner dalam penyelenggaraan program riset di perguruan tinggi. Berdasarkan analisis terhadap literatur, ditemukan bahwa pustakawan akademik memiliki peran yang strategis dalam kesuksesan program riset. Secara umum peran pustakawan akademik dalam kegiatan riset ditunjukan pada perannya dalam memberikan konsultasi riset, melaksanakan program pengajaran kemampuan riset, dan membantu dalam penerbitan dan penyebarluasan hasil-hasil riset. Pustakawan tidak hanya melayani dan mendampingi peneliti secara individual dalam melakukan kegiatan riset, tetapi juga merencanakan dan melaksanakan program-program secara kelompok atau program-program kelas dalam memberikan pengajaran kemampuan riset melalui program pendidikan literasi informasi bagi para sivitas akademika. Melalui pengajaran literasi informasi, para sivitas akademika dibekali kemampuan mengenali sumber-sumber informasi, kemampuan menelusur informasi, dan mengelola sitasi.
\end{abstract}

Kata kunci: perpustakaan universitas, pustakawan akademik, konsultan riset, literasi informasi, penerbitan karya ilmiah

\section{A. PENDAHULUAN}

Salah satu tugas utama suatu perguruan tinggi adalah memproduksi ilmu pengetahuan (knowledge production). Keberadaan perguruan tinggi diharapkan mampu memberikan kontribusi dalam menghasilkan dan mengembangkan ilmu pengetahuan, temuan serta inovasi yang berguna bagi kehidupan masyarakat dan bangsa. Para sivitas akademika, karenanya, didorong untuk

melakukan berbagai kegiatan riset yang hasilnya dapat berguna tidak hanya untuk kepentingan keilmuan, tetapi juga untuk kepentingan kemanusiaan.

Untuk memperkuat fungsi riset perguruan tinggi, pemerintah kemudian menggabungkan pendidikan tinggi dalam Kementerian Riset dan Teknologi. Oleh banyak kalangan, 
dimasukannya pendidikan tinggi dalam suatu kementerian sehingga menjadi Kementerian RisTek dan Dikti dinilai sangat tepat. Melalui penggabungan ini diharapkan perguruan tinggi benar-benar menjadi basis riset nasional, dan menjadi instrumen penting dalam kemajuan dan kesejahteraan bangsa (Pratomo, 2014; Haryadi, 2014). Selain itu, penggabungan ini juga dapat mempercepat kebijakan pendidikan nasional menuju terwujudnya perguruan tinggi atau universitas berbasis riset, atau dikenal dengan universitas riset (research university).

Untuk mewujudkan visi riset perguruan tinggi, keterlibatan semua komponen pendidikan tinggi dan peran aktif dari segenap masyarakat kampus merupakan suatu keharusan. Selain tersedianya anggaran yang cukup dan fasilitas serta infrastruktur yang memadai untuk kegiatan riset, kerjasama dan kemitraan merupakan pondasi bagi keberlangsungan program riset di perguruan tinggi. Dalam hal ini, perpustakaan dan pustakawan merupakan bagian penting dalam kegiatan riset perguruan tinggi. Selain ketersediaan sumber-sumber informasi atau literature di perpustakaan, para pustakawan akademik juga harus didorong untuk memainkan peran yang strategisnya sebagai mitra atau partner dalam kegiatan riset para sivitas akademika perguruan tinggi.

Makalah ini dimaksudkan untuk memberikan penjelasan mengenai peran pustakawan akademik sebagai mitra riset sivitas akademika perguruan tinggi.

\section{B. PEMBAHASAN}

\section{Perubahan Peran Pustakawan Akademik}

Secara umum, yang dimaksud dengan pustakawan akademik adalah para pustakawan yang bekerja di perpustakaan perguruan tinggi. Tanggung jawab atau peran utama pustakawan akademik adalah mendukung terselenggaranya berbagai kegiatan akademik perguruan tinggi. Dalam konteks Indonesia, kegiatan akademik tersebut tercantum dalam program Tri Dharma perguruan tinggi yaitu mencakup kegiatan pendidikan dan pengajaran, penelitian, dan pengabdian masyarakat. Oleh karena itu pustakawan di lingkungan perguruan tinggi harus mampu bekerja sama dengan masyarakat akademik seperti dosen, mahasiswa, dan staf universitas lainnya demi tercapainya tujuan pergruruan tinggi yang bersangkutan.

Selain harus memahami sistem sosial tempat bekerja, pustakawan juga dituntut untuk memahami lingkungan tugas sebagai pustakawan. Pustakawan sebagai seorang profesional di bidang perpustakaan dan informasi dihadapkan dengan perubahan yang terjadi di lingkungan tugasnya. Perkembangan teknologi komunikasi dan informasi (TIK) telah membawa pengaruh yang siginifikan di bidang perpustakaan. Selain mengubah paradigma kepustakawanan, perkembangan TIK juga berpengaruh terhadap tata kelola dan penyelenggaraan perpustakaan. Perubahan ini juga menuntut perpustakaan, terutama perpustakaan perguruan tinggi untuk menata kembali perannya di tengahtengah masyarakat, baik masyarakat kampus maupun masyarakat secara lebih luas. Siregar (2008) menekankan pentingnya perpustakaanperpustakaan akademik melakukan reorientasi fungsi dengan mempertimbangkan penataan lingkungan perpustakaan yang lebih disenangi oleh para mahasiswa, serta mengoptimalkan para dosen sebagai sumber daya utama dalam melayani para mahasiswa dengan cara memperkaya akses informasi guna meningkatkan produktifitas para dosen dalam menghasilkan karya-karya ilmiah. Selain itu, perpustakaan akademik juga didorong untuk dapat mempublikasi hasilhasil riset para sivitas melalui media yang dapat menjangkau masyarakat secara luas.

Selain secara kelembagaan, perubahan tersebut juga berpengaruh terhadap peran pustakawan pada level individu. Dalam salah satu tulisan tentang peran pustakawan, Also dkk (2007) mengidentifikasi pentingnya pustakawan akademik untuk berperan lebih aktif dan menjalin hubungan dengan pihak-pihak lain pada tingkat universitas. Pustakawan akademik harus mampu menunjukkan eksistensinya di tengah-tengah masyarakat kampus lainnya.

Berkaitan dengan perubahan peran ini, dalam hal ini suatu kutipan dari Rice-Lively 
and Racine (1997) menarik untuk dicermati. Dalam salah satu tulisannya yang berjudul The Role of Academic Librarian in the Era of Information Technology, Rice-Lively and Racine (1997) mengemukakan bahwa "the function of the librarian seemed to be evolving from the keeper of the books to that of network navigator". Kutipan ini menunjukkan adanya perubahan peran pustakawan akibat terjadinya perubahan lingkungan tugas. Pustakawan akademik, menurut Rice-Lively and Racine (1997), telah mengalami perubahan peran dari seorang penjaga buku menjadi seorang navigator jaringan (network navigator). Perkembangan teknologi informasi telah menyebabkan produksi informasi berlimpah ruah, dan tersebar dalam berbagai pangkalan data yang satu dengan lainnya terhubung dalam suatu jaringan global. Oleh karena itu, pustakawan akademik tidak lagi terbatas pada menyediakan bahan-bahan yang diperlukan pemustaka dan secara pasif menunggu dan melayani kebutuhan informasi para pemustaka, akan tetapi harus secara proaktif mengarahkan pemustaka pada sumbersumber informasi yang secara potensial relevan dengan kebutuhannya.

Tentu saja untuk menjalankan peran tersebut, pustakawan akademik sebagai profesional informasi dituntut untuk memiliki kualifikasi dan kompetensi di bidang perpustakaan. Kualifikasi berkaitan dengan latar belakang dan tingkat pendidikan pustakawan, sedangkan kompetensi menyangkut kemampuan seorang pustakawan dalam melaksanakan tugas-tugas kepustakawanan di perguruan tinggi. Latar belakang dan tingkat pendidikan seorang pustakawan memiliki pengaruh yang besar dalam pelaksanaan tugas-tugas kepustakawanan. Demikian juga kompetensi, pustakawan akan dapat bekerja secara efektif dan efisien apabila didukung oleh kompetensi yang sesuai dengan pekerjaan yang menjadi tanggung jawabnya.

Dalam kaitannya dengan kompetensi pustakawan akademik, Farmer (2007) menekankan pentingnya pustakawan akademik untuk memiliki empat kemampuan fundamental, yaitu (1) pengetahuan secara umum atau wawasan ilmu pengetahuan, (2) pengetahuan tentang perpustakaan, (2) pengetahuan tentang riset, dan (4) pengetahuan tentang teknologi.

Sementara secara khusus Kumar (2007) menegaskan bahwa kemajuan di bidang TIK mengharuskan pustakawan akademik untuk mengikuti perubahan yang terjadi, dan menyesuaikan peran dengan perubahan tersebut dalam rangka memberikan layanan perpustakaan yang berorientasi pada pemanfaatan teknologi. Untuk menjalankan peran di era teknologi, pustakawan akademik harus (1) menguasai teknologi yang diterapkan di perpustakaan, (2) dapat membantu pemustaka dalam mendapatkan informasi yang diperlukan, (3) memiliki pengetahuan berkaitan dengan manajemen informasi digital, (4) beradaptasi dengan berbagai perubahan perkembangan teknologi (Kumar, 2009).

\section{Peran Pustakawan dalam Riset di Perguruan Tinggi}

Salah satu peran penting yang harus dilakukan oleh pustakawan akademik adalah sebagai mitra atau partner dalam kegiatan riset di perguruan tinggi. Riset sebagai suatu karakteristik utama suatu perguruan tinggi perlu mendapatkan penguatan dari seluruh komponen universitas, tidak terkecuali pustakawan. Tentu saja, penguatan ini akan sangat beragam tergantung dari kapasitas dan kapabilitas masing-masing dari masyarakat kampus. Tugas pimpinan universitas adalah menyediakan anggaran dan fasilitas lainnya yang mendukung terselenggaranya riset di perguruan tinggi. Sedangkan staf administrasi diharapkan dapat memfasilitasi penyelenggaraan riset secara administrasi sehingga para peneliti tidak terbebani dengan berbagai persoalan administrasi yang secara substantif tidak berkaitan dengan kegiatan riset. Bagaimana halnya dengan para pustakawan?

Menurut Kennedy \& Brancolini (2012), pustakawan akademik harus mampu bekerjasama dengan para sivitas akademika, baik dosen maupun mahasiswa dalam berbagai kegiatan penelitian. Salah satu tugas utama pustakawan akademik adalah menjamin 
terselenggaranya kegiatan riset di perguruan tinggi melalui penyediaan sumber-sumber yang diperlukan dan menyelenggarakan program instruksional yang diperlukan untuk mendukung kegiatan riset. Farmer (2007) menekankan pentingnya pustakawan akademik untuk memiliki pengetahuan tentang riset agar mereka dapat memberikan pengajaran kepada para mahasiswa halhal yang diperlukan dalam kegiatan riset. Selanjutnya, dalam satu paper berjudul "Engaging Research: Libraries in a Shifting Academic Paradigm" yang disampaikan pada kongres IFLA ke 78 di Helsinki tahun 2012, Luce \& Grohsgal (2012) menjelaskan bahwa pustakawan akademik harus berkontribusi dalam kegiatan riset di perguruan tinggi.

Secara garis besar, partnership antara pustakawan akademik dan sivitas akademika dalam kegiatan riset di perguruang tinggi dijelaskan sebagai berikut.

\section{Konsultasi Riset (research consultant)}

Salah satu tugas utama perpustakaan akademik adalah menjamin terselenggaranya kegiatan riset di perguruan tinggi. Untuk menjalankan tugas tersebut, pustakawan akademik harus dapat melayani para sivitas akademika, terutama untuk keperluan riset. Jaguszewski dan Williams (2013) dalam pembahasannya tentang liaison librarian mengemukakan beberapa peran penting pustakawan akadamik dalam kegiatan riset di perguruan tinggi. Menurutnya, pustakawan akademik harus dapat berperan sebagai konsultan riset (research consultant). Melalui layanan referensi (reference desk service), pustakawan akademik melayani para peneliti baik dari kalangan mahasiswa maupun dosen untuk mendapatkan sumber-sumber informasi yang diperlukan, dan atau membimbing mereka dalam menggunakan perangkat teknologi dalam menelusur informasi seperti database online, jurnal elektronik, dan lain-lain.

Ballmer (2016) menyebutkan beberapa hal yang harus dilakukan pustakawan akademik dalam memberikan layanan informasi riset, yaitu meliputi :

a Membantu pemustaka menemukan bahanbahan atau sumber-sumber informasi yang diperlukan, dan menawarkan bimbingan proyek riset secara lebih dalam

b Menjawab pertanyaan referens, baik secara langsung, online atau melalui telepeon

c Membantu dalam penggunaan katalog, databatase, dan sumber-sumber informasi online lainnya

d Membantu menemukan sumber informasi yang berada di luar atau di perpustakaan lain

e Membantu para dosen mendapatkan hasilhasil riset terdahulu berkenaan dengan subjek penelitian

Berkaitan dengan konsultasi riset, Stamatoplos (2009) bahkan menyatakan bahwa pustakawan akademik harus berperan dalam membimbing atau menjadi mentor kegiatan penelitian bagi mahasiswa tingkat sarjana (undergraduate).

\section{Pengajaran Kemampuan Riset (research skills)}

Selain memberikan informasi untuk keperluan riset, pustakawan akademik juga berperan dalam pemberian pengajaran kepada sivitas akademika kemampuankemampuan yang diperlukan dalam kegiatan riset. Banyak perpustakaan-perpustakaan perguruan tinggi yang telah melakukan peran ini dalam bentuk pemberian kemampuan riset berbasis perpustakaan atau library research skills. Program ini menjadi tanggung jawab dan tugas dari pustakawan akademik.

$$
\text { Jaguszewski dan Williams }
$$
menekankan pentingnya program pengajaran kemampuan riset (research skill) bagi para sivitas akademika yang dilakukan oleh pustakawan akademik. Pustakawan akademik dituntut untuk dapat merencanakan dan menyelenggarakan program pendidikan literasi informasi (information literacy) yang diarahkan memberikan bekal kemampuan bagi para sivitas akademika dalam melakukan riset. Selanjutnya, Ballmer (2016) menyebutkan bahwa tiga hal yang harus dilakukan pustakawan akademik berkenaan dengan pengarajaran informasi untuk keperluan riset, yaitu (1) memberikan orientasi perpustakaan, (2) mengajarkan kemampuan spesifik mengenai teknik dan alat riset, dan (3) mengajarkan kemampuan 


\section{literasi riset dan informasi}

Berkaitan dengan pengajaran kemampuan riset, beberapa kemampuan dasar yang penting diberikan kepada para sivitas akademika antara lain adalah sebagai berikut;

\section{a. Kemampuan mengenali sumber- sumber informasi}

Kegiatan riset memerlukan dukungan sumber-sumber informasi atau literatur yang memadai. Sumber-sumber informasi diperlukan sebagai dasar untuk memahami topik yang menjadi bahan kajian, dan untuk melihat hasil-hasil kajian atau penelitian yang sudah dilakukan oleh orang lain berkenaan dengan topik. Pustakawan akademik, oleh karenanya, harus mampu mengajarkan kepada para sivitas akademika berkenaan dengan jenis-jenis dan bentuk-bentuk sumber-sumber informasi yang relevan dengan riset yang sedang dilakukannya.

Dilihat dari karakteristik atau sifat informasi, misalnya, sumber-sumber informasi dapat dibedakan ke dalam sumber informasi primer, skunder, dan tertier. Masing-masing jenis sumber informasi ini memiliki fungsi yang berbeda dalam kegiatan riset. Untuk memperoleh pemahaman awal mengenai suatu topik, peneliti dapat menggunakan sumber informasi sekunder seperti buku teks, dan ensiklopedia. Akan tetapi, untuk keperluan literature review, seorang peneliti memerlukan sumber-sumber informasi primer seperti jurnal ilmiah atau refereed journal, laporan teknis, dan lain-lain. Selain itu, peneliti juga memerlukan sumber informasi bibliografi atau sumber tersier untuk mendapatkan sumber primer atau sumber sekunder seperti bibliografi.

Selain memahami karakteristik terbitan atau sumber informasi, peneliti juga harus menguasai bentuk-bentuk terbitan, terutama dalam bentuk elektronik. Hal ini karena dewasa ini sumber-sumber informasi tersebut telah diterbitkan dalam bentuk elektronik seperti e-book, ejournals, dan online database. Pengetahuan dan penguasaan seseorang terhadap sumber-sumber informasi elektronik sangat membantu dalam mendapatkan informasi yang diperlukan untuk kegiatan riset. Sumber-sumber informasi primer, sekunder, dan tersier kini telah banyak diterbitkan dalam bentuk elektronik, dan karenanya penguasaan terhadap sumbersumber elektronik akan sangat membantu peneliti dalam melakukan kegiatan riset. Secara umum, terdapat sumber-sumber informasi elektronik yang menyediakan informasi secara fulltext dan yang hanya menyediakan sumber informasi bibliografi.

Di era teknologi, sumber-sumber informasi yang memuat informasi secara fulteks tersimpan dalam suatu database yang dapat diakses secara online. Terdapat database yang menyediakan akses secara bebas atau gratis, dan akses berbayar. Di antara database yang menyediakan akses secara fulteks adalah ScienceDirect, SpringerLink, Cengage, J-Stor, Emerald, dan lain-lain.

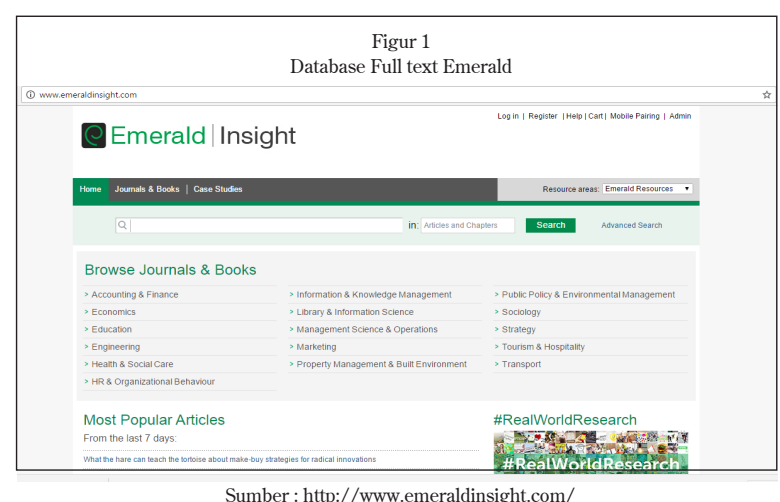

Selain database yang menyediakan akses fulteks, terdapat juga database yang menyediakan akses pada level data bibliografi atau bibliographic databases. Bibliographic database merupakan database yang berisi informasi mengenai cantuman deskriptif tentang buku, artikel jurnal, prosiding, dam koleksi audio-visual. Termasuk dalam jenis ini adalah katalog perpustakaan seperti katalog OCLC atau WolrdCat dan OneSearch Gate, atau database jurnal seperti ISI Web of Knowledge, Scopus, dan lain-lain. Untuk subyek yang spesifik, terdapat Index Islamicus, Anthropological Index Online, dan Index to the Study of Religious. 


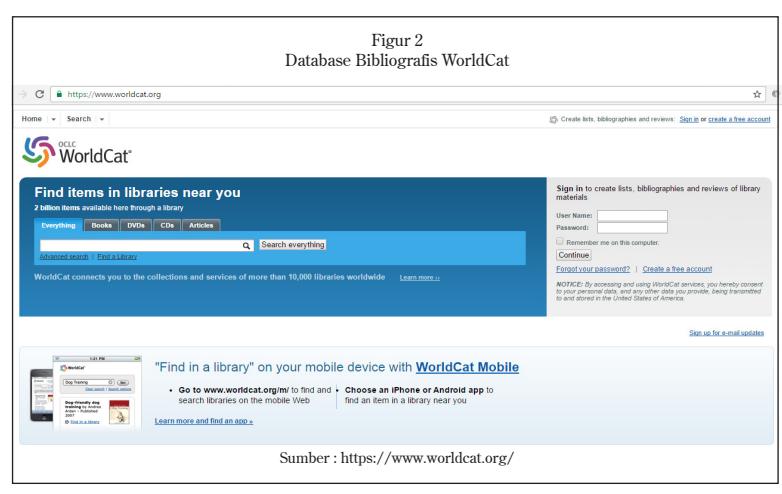

\section{b. Kemampuan Penelusuran Informasi}

Salah satu kemampuan riset (research skill) yang penting diberikan kepada para sivitas akademika adalah kemampuan menelusur dan menemukan informasi yang diperlukan untuk kegiatan riset. Seorang peneliti memerlukan dukungan literatur yang cukup untuk membahas topik yang dikaji. Selain itu mereke juga memerlukan literatur berkenaan dengan hasil-hasil riset sebelumnya (literature review). Untuk mendapatkan literatur yang diperlukannya, seorang peneliti harus memiliki kemampuan penelusuran informasi. Pustakawan akademik, dalam hal ini, dituntut untuk berperan memberikan pengajaran informasi berkenaan dengan teknik dan strategi penelusuran, serta menjelaskan sumber-sumber informasi yang secara potensial dapat digunakan dalam penelitian.

Kemampuan menelusur informasi ini menjadi semakin penting di era teknologi. Di era ini, produksi informasi dan penerbitan berlangsung dengan sangat cepat dan jumlahnya dangat masif. Dari aspek penerbitan, perkembangan dalam dunia publishing telah mendorong publikasi elektronik dan digital yang dapat diakses secara online. Ketersediaan digital resources ini harus diikuti oleh kemampuan mengakses dan menelusur sumber online yang dapat didaya gunakan untuk melakukan riset-riset akademik. Menurut Marchionini (1998) strategi penelusuran sumber-sumber online akan membantu didalam menemukan ketepatan sumber informasi didalam online databases. Keahlian menelusur akan memperkaya peneliti dengan literatur ilmiah dalam berbagai sumber (buku, jurnal,majalah,prosiding, database elektronik) yang akan menghasilkan riset ilmiah yang reliable dan handal.

Dalam kaitannya dengan kemampuan menelusur dan menemukan informasi yang diperlukan untuk kegiatan riset, pustakawan akademik perlu mengenalkan dua aspek penting, yaitu (1) mengenalkan alat sumbersumber informasi, dan (2) mengenalkan strategi penelusuran terhadap sumber informasi.

1) Pengenalan tehadap Alat Penelusuran Informasi

Dalam kegiatan penelusuran informasi , seorang peneliti juga perlu menguasai alat penelusuran yang akan digunakan untuk mendapatkan sumber informasi yang diperlukan. Alat penelusuran dimaksud adalah sarana yang digunakan untuk menelusur atau menemukan informasi yang diperlukan. Di perpustakaan, alat-alat penelusuran informasi tersebut berupa katalog, bibliografi, dan indeks. Sedangkan, di website atau sumber informasi dalam jaringan internet, alat telusur tersebut berupa search engine dan directory.

Banyaknya informasi yang tersedia internet tersebut memerlukan keahlian di dalam menelusurnya. Beberapa perusahaan komersial kemudian menjadikan hal ini sebagai peluang untuk menciptakaan mesin pencari informasi yang disebut search engine. Melalui search engine, kumpulan informasi tersebut ditata atau diindeks sedemikian rupa sehingga membentuk kategori tertentu yang dapat memudahkan para pemakai dalam menelusurnya. Tujuan search engine adalah untuk mempermudah pengguna dalam melakukan pencarian suatu informasi di internet. Program search engine merupakan program yang menyaring berjutajuta halaman situs yang tersimpan diindex untuk dicari kesamaan dari pencarian dan mengurutkannya dalam urutan yag kira-kira relevan dengan kata kunci deskripsi. Di antara serach engine yang sangat bermanfaat bagi peneliti adalah Google Scholar atau Google Cendekia. 


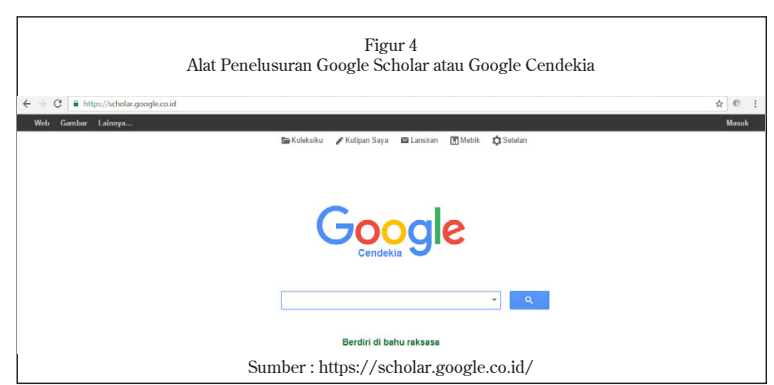

Dalam kaitannya dengan kegiatan riset, Google Scholar menawarkan bantuan untuk menemukan informasi atau artikel ilmiah, baik secara fulteks langsung maupun merujuk pada suatu jurnal tertentu. Selain itu, Google Scholar juga menyediakan saran untuk membuat sitasi atau rujukan pada artikel yang ditemukan berdasarkan gaya rujukan seperti APA, MLA, dan ISO 690.

Selain search engine, alat telusur sumber elektronik lainnya adalah direktori. Di antara directory yang penting diketahui oleh para peneliti adalah direktori open access journal atau disingkat DOAJ. Direktori ini menyediakan akses ke jurnal-jurnal berikut artikel yang dimuat yang dapat diakses secara gratis atau free.

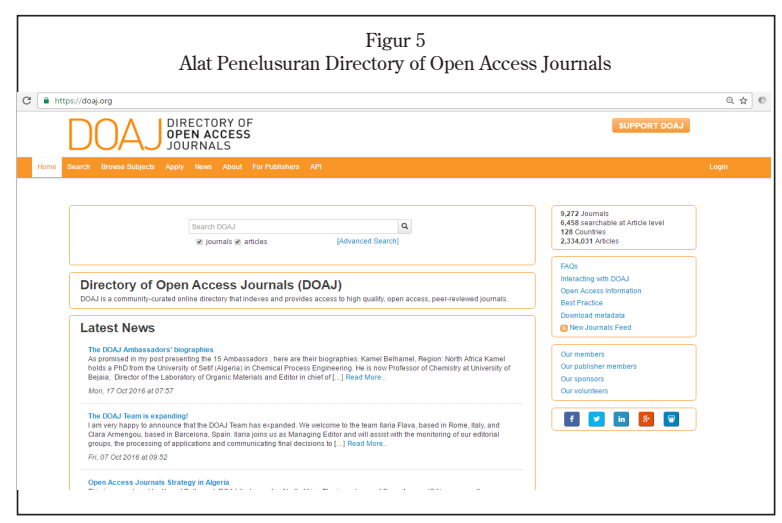

2) Penggunaan Alat dan Strategi Penelusuran

Setelah menentukan alat penelusuran yang digunakan, langkah selanjutnya adalah merumuskan strategi penelusuran. Dalam tahap ini, menurut Marchionini (1998), terdapat beberapa konsep yang perlu dipahami oleh seorang peneliti, yaitu mencakup sebagai berikut :

a) Kemampuan mendefenisikan dan memahami masalah penelitian dengan merumuskan konsep - konsep kunci (key concepts) dan konsep-konsep yang berkaitan (relationship)

b) Kemampuan memilih sistem penelusuran

c) Kemampuan memformulasikan query

d) Kemampuan melaksanakan penelusuran

e) Kemampuan mengevaluasi hasil penelusuran (exemine search)

Secara skematis, proses penelusuran informasi tersebut digambarkan Marchionini (1998) pada figure 6.

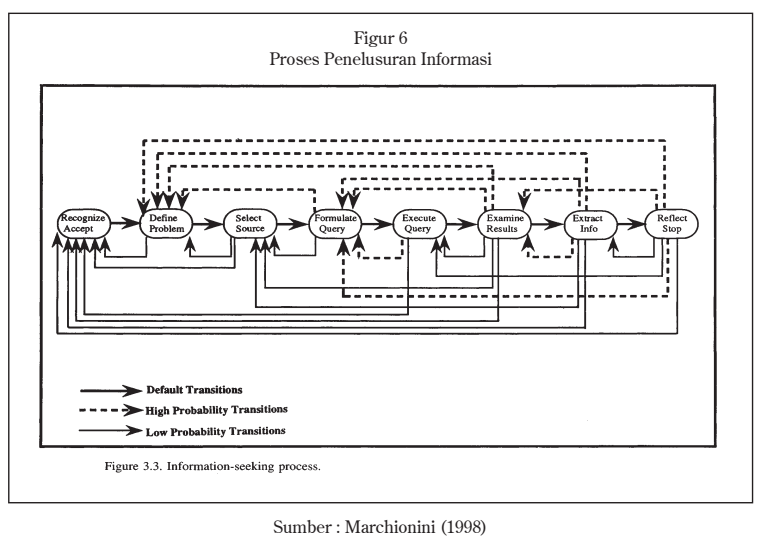

Skema tersebut menggambarkan bahwa proses penelusuran dimulai ketika seorang peneliti menyadari adanya kebutuhan informasi. Kebutuhan informasi tersebut berkaitan dengan keterbatasan peneliti dalam memahami topik penelitian, baik secara konseptual maupun dalam mendapatkan literatur yang berkaitan. Untuk mendapatkan literatur yang benar-benar relevan dengan kebutuhan tersebut. Pustakawan akademik terutama pustakawan referens dapat berperan mendampingin peneliti dengan melakukan wawancara referens (reference interview) untuk memastikan kebutuh informasi peneliti. Dalam tahap ini, beberapa konsep kunci (key concepts) dan konsep yang relevan diidentifikasi untuk menggambarkan kebutuhan informasi.

Langkah selanjutnya adalah menentukan sumber informasi yang akan digunakan untuk mencari informasi. Dalam tahap ini, pustakawanakademikdapatmembantupeneliti dalam menggunakan sarana penelusuran seperti katalog, indeks, atau menggunakan pangkalan data (database) untuk menemukan informasi yang diperlukan tersebut. Setelah menentukan sumber informasi atau system 
penelusuran yang akan digunakan, langkah berikutnya adalah merumuskan permintaan atau queri. Permintaan ini berupa konsep atau gabungan konsep yang mewakili kebutuhan informasi yang akan diajukan atau dimasukan dalam system penelusuran. Dalam sistem penelusuran online, queri ini bersifat lebih dinamis karena pencarian informasi dapat dilakukan dalam banyak alternatif teknik pencarian seperti melalui kosa kata terkendali (controlled vocabularies), atau kosa kata fulteks (full text vocabulary). Untuk mengeksekusi permintaan, pencari informasi dalam sistem online hanya mengetik kata cari tersebut dalam suatu sistem. Beberapa sistem pencarian menyediakan sistem pencaraian sederhana (simple search), dan sistem pencarian lebih lanjut (advance serach). Pada advance search, pencari informasi dapat melakukan pembatasan dalam pencarian informasi tergantung dari kebutuhan informasinya seperti lingkup subyek, tahun penerbitan, bentuk sumber informasi dan lain-lain. Beberapa sistem penelusuran kini telah menyediakan sarana penelusuran secara berfaset yang memberikan pilihan-pilihan bagi pencari informasi untuk membatasi penelusuran informasi berdasarkan kriteria tertentu.

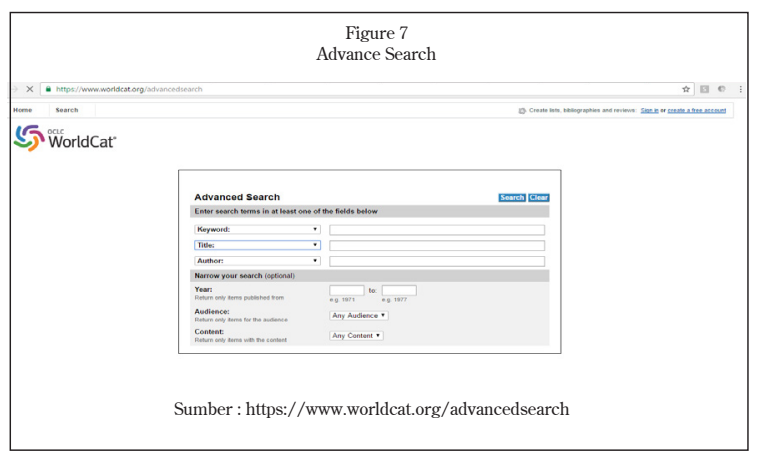

Selanjutnya, berdasarkan informasi yang ditemukan oleh sistem, peneliti akan menilai dengan memilih dan memilah informasi berdasarkan kebutuhan infromasi. Informasi yang benar-benar relevan dengan kebutuhannya akan digunakan untuk keperluan risetnya.

\section{c. Mengelola sitasi (managing citations)}

Selain mengajarkan tentang sumbersumber informasi dan penggunaan alat penelusuran serta strategi penelusuran, hal lainnya yang penting diajarkan kepada para sivitas akademika adalah pengelolaan sitasi. Pengelolaan sitasi merupakan aspek penting dalam penulisan karya ilmiah, termasuk dalam penyusunan hasil penelitian. Menerbitkan laporan penelitian baik dalam bentuk monograf atau artikel jurnal memerlukan ketrampilan dalam pengelolaan sitasi. Sitasi atau pengutipan merupakan kegiatan mengambil ide atau gagasan orang lain dan menjadikannya sebagai bagian dari suatu karya.

Dalam penyusunan karya ilmiah, pengelolaan sitasi menjadi aspek krusial yang harus diperhatikan para peneliti agar terhindar dari isu plagiarisme. Saat ini banyak sekali sarana-sarana pengelolaan bibliografi (bibliographic management tools) yang tersedia yang dapat digunakan oleh para peneliti, mahasiswa dan para sivitas akademika didalam menyimpan, mengorganisasikan dan mengelola referensi atau sumber-sumber rujukan ketika menulis laporan penelitian, tesis, disertasi, artikel jurnal dan publikasi lainnya. Ada beberapa sarana manajemen referensi yang popular digunakan oleh kalangan peneliti didalam mengelola sumbersumber rujukan penelitian, yaitu :
a) CiteUlike
b) Colwiz
c) EndNote Onlin (www.citeulike.org) (www.colwiz.com) com)
d) EndNote Desktop (www.endnote.com)
e) Mendeley (www.mendeley.com)
f) Papers
g) ReadCube
h) RefWorks
i) Zotero
(www.papersapp.com) (www.readcube.com) (www.refworks.com) (www.zotero.org)

Dari sejumlah sarana manajemen referensi diatas, EndNote, Mendeley dan Zotero merupakan reference management tools yang paling popular dan paling banyak digunakan. Reference management tools meruapakan materi atau kemampuan yang harus diajarkaan pada pengajaran research skills dalam program literasi informasi bagi para sivitas akademika. 
3. Penerbitan dan Penyebarluasan Hasil-hasil Riset

Peran pustakawan akademik lainnya dalam kegiatan riset di perguruan tinggi berkaitan dengan kegiatan penerbitan dan penyebarluasan hasil-hasil penelitian para sivitas akademika.

Ada beberapa hal yang dapat dilakukan pustakawan akademik pada tahap penerbitan dan penyebarluasan hasil-hasil penelitian, yaitu sebagai berikut :

\section{a. Refereed versus Predatory Journals}

Jurnal atau majalah ilmiah merupakan sarana komunikasi terpenting bagi para sivitas akademika atau peneliti. Jurnal ilmiah menyajikan informasi ilmiah hasil-hasil penelitian yang dilakukan oleh ahli. Salah satu persoalan penting dalam penerbitan hasil penelitian adalah pemilihan jurnal yang sesuai dengan hasil penelitian. Pustakawan akademik dapat memberikan informasi dan menyarankan para peneliti untuk menerbitkan hasil-hasil penelitiannya pada jurnal-jurnal yang terakreditasi, atau jurnal yang kredibel atau refereed atau reviewed journals.

Untuk keperluan praktis, terutama jurnal-jurnal yang diakui sebagai media publikasi dan komunikasi ilmiah para dosen dan peneliti kampus, Kementrian Riset, Teknologi dan Pendidikan Tinggi menyarankan untuk menhindari penerbitan pada media berikut :

1) Jurnal palsu berdasarkan Surat Direktur Diktendik seperti jurnal JAM, Didaktika, dan Agritek

2) Jurnal Nasional tidak terakreditasi dan meragukan seperi jurnal PERCIKAN oleh IKBUJ, jurnal INOVASI oleh Himpunan Mahasiswa dan Alumni Pascasarjana asal SUMUT, jurnal Aktualita oleh Kantor KPN- Kopertis wilayah IX Sulawesi, dan lain-lain

3) Jurnal Internasional Palsu seperti International Journal of Business and Social Science (USA), dan Asian Social Science (Canada)

4) Jurnal yang dipertanyakan

\section{(questionable journals)}

Berdasarkan hal tersebut, beberapa hal yang penting dilakukan oleh pustakawan akademik adalah sebagai berikut:

a) Untuk jurnal nasional, pustakawan dapat menyarankan para penelitin untuk merujuk jurnal-jurnal yang terakreditasi oleh Dirjen Penguatan Risetdan Pengembangan, Kementrian Riset, Teknologi dan Pendidikan Tinggi (2016), atau Database jurnal Ilmiah Indonesia (2016).

b) Untuk penerbitan artikel jurnal internasional, Pustakawan juga harus menginformasikan jurnaljurnal yang termasuk dalam kategori predatory journals atau jurnal yang tidak diakui. Beall (2016) mendaftar lebih dari 923 jurnal termasuk dalam kategori predatory journals.

c) Sedangkan untuk jurnal-jurnal yang diakui, jurnal-jurnal tersebut harus diindeks dalam ISI (International Scientific Indexing) atau Scopus. Untuk mengecek profil jurnal dan tingkat kredibilitas suatu jurnal ilmiah yang diindeks dalam Scopus dapat dilihat dari SCimago Journal Rank atau SJR (http://www. scimagojr.com/).

b. Standar format penulisan artikel

Selain pemilihan jurnal yang kredibel dan sesuai bidang keilmuan, standar atau format penulisan suatu jurnal juga perlu dipertimbangkan dalam penerbitan suatu artikel. Beberapa jurnal terakreditasi baik tingkat nasional maupun internasional memiliki gaya penulisan dan format yang berbeda. Pustakawan akademik, karenanya dapat menginformasikan dan mengajarkan gaya-gaya penulisan dan format yang dikehendaki oleh masingmasing jurnal. Secara umum, menuurt Indrawan (2008), format artikel dalam jurnal ilmiah -kajian konseptual maupun hasil penelitian empiris- pada 
umumnya mencakup, bagian: (1) judul, (2) nama penulis, (3) abstrak dan katakata kunci, (4) pendahuluan, (5) isi (6) penutup atau rangkuman, dan (7) daftar rujukan/pustaka.

Berikut ini adalah contoh format dan gaya penulisan beberapa jurnal ilmiah. Untuk format artikel jurnal yang diindeks oleh ISI, format artikel terdiri dari aspek-aspek sebagai berikut :

1) Project title

2) Abstract

3) Introduction

4) Methods

5) Results and Discussion

6) Conclusioins and Future Conside-ration

Rincian dari masing-masing aspek dapat dilihat lebih lanjut pada template artikel riset ISI. Untuk jurnal-jurnal bidang teknologi yang tergabung dalam IEEE dapat dilihat pada IEEE.org.

c. Penyebarluasan Hasil Penelitian dalam Institutional Repositories

Selain dalam proses riset, pustakawan akademik mitra riset memiliki peran dalam penyebarluasan hasil-hasil penelitian dalam repository universitas. Repositori universitas atau sering disebut dengan institutional repositories merupakan koleksi digital yang menyimpan hasil karya intelektual dari satu atau beberapa masyarakat universitas (Crow, 2002; Lynch, 2003). Koleksi-koleksi digital yang dapat dikelola dalam Institutional Repository tersebut menurut Bailey (2008) dan Crawford (2011), mencakup beragam jenis yang dihasilkan oleh para ilmuwan dari berbagai unit, misalnya laporan teknis, laporan penelitian, skripsi, tesis, disertasi, gambar digital, bahan garfis, dan bahan bahan ajar.

Pengelolaaninstitutionalrepository di kalangan perguruan tinggi selain untuk penyimpanan dokumen universitas (McGovern, 2008), dan untuk penyediaan akses terbuka terhadap berbagai terbitan sebagai bentukkomunikasiilmiahdikalangan ilmuwan (Wust, 2006; Palmer, 2008 ; Duranceau, 2008; Crawford, 2011), atau untuk peningkatan kinerja lembaga / universitas (Johnson, 2002; Bailey, 2008), open access repository ini diharapkan dapat meningkatkan kualitas pembelajaran dan penelitian yang dilakukan oleh para sivitas akademika (McCord, 2003).

Dalam kerangka penyebarluasab hasil-hasil penelitian melalui sistem institutional repository, menurut Bailey (2008) pustakawan akademik terutama pustakawan referens memiliki peran sebagai berikut :

1) Merumuskan kebijakan dan prosedur pengembangan repsoitori

2) Memberi masukan dalam pengembangan interface sistem repositori

3) Membantu dalam identifikasi kegiatan self-archiving

4) Mempromosikan repositori di kalangan sivitas akademika

5) Menjelaskan tentang kebijakan lisensi penerbitan (Creative Commons Licensing)

6) Membantu dalam proses deposit

7) Melakukan verifikasi terhadap metadata repositori

8) Memberikan pelatihan penggunaan sistem repositori

9) Membantu dalam pemanfaatan repsoitori

Uraian tersebut menunjukkan bahwa pustakawan akademik memiliki peran yang strategis dalam kegiatan riset di perguruan tinggi. Mulai dari tahap persiapan riset, pelaksanaan riset, dan pasca kegiatan riset, terdapat ruang-ruang bagi pustakawan untuk bekerjasama dengan para sivitas akademika dalam kegiatan riset. Oleh karena itu penting, bagi pustakawan untuk memperkuat kompetensi terutama dengan membekali kemampuan yang diperlukan dalam pemberian layanan informasi untuk riset maupun untuk melaksanakan programprogram pengajaran literasi informasi bagi para sivitas akademika. 


\section{PENUTUP}

Perpustakaan memiliki peran yang strategis dalam penyelanggaraan program Tri Dharma perguruan tinggi, khusus dalam kegiatan riset. Selain menyediakan sumbersumber yang diperlukan untuk kegiatan riset, perpustakaan melalui pustakawan akademik juga berperan dalam memberikan layanan dan edukasi tentang riset. Pustakawan akademik dapat menyediakan layanan konsultasi riset, dan menyelenggarakan pengajaran kemampuan riset (research skill) melalui program pendidikan literasi informasi bagi para sivitas akademika.

\section{DAFTAR PUSTAKA}

Alsop, J., \& Bordonaro, K. (2007). Multiple roles of academic librarians. Electronic Journal of Academic and Special Librarianship, 8(1). Diakses tgl. 5 November 2016 dari http:// southernlibrarianship.icaap.org/content/ v08n01/alsop_j01.htm

Article Templates and Instructions. Diakses tanggal 10 November 2016 dari https:// www.ieee.org/publications_standards/ publications/authors/author_templates. html

Bailey, C. W. (2008). Institutional Repositories , Tout de Suite. San Francisco, California. Retrieved January 03, 2013 from http:// digital-scholarship.org/ts/irtoutsuite.pdf

Ballmer, Amy (2016). Research \& Instructional Services. New York: State University. Diakses tgl. 5 November 2016 dari https:// www.fitnyc.edu/library/research/

Beall, Jeffrey (2016). Beall's List of Predatory Open Access Publisher. Diakses tanggal 10 November 2016 dari https://scholarlyoa. com/2016/0 1/ 05 / b ealls-list - of predatory-publishers-2016/

Crawford, W. (2011). Open access: what you need to know now. American Library Association.

Crow, R. (2002). The Case for Institutional Repositories: A SPARC Position Paper. Scholarly Publishing, 1-37. Retrieved January 03, 2013 from http://www.arl.org/ sparc/bm doc/ir_final_release_102.pdf

Directory of Open Access Journals (DOAJ). (2016). Diakses tanggal 10 November 2016 dari https://doaj.org/

Dirjen Penguatan Riset dan Pengembangan, Kementrian Riset, Teknologidan Pendidikan Tinggi (2016). Akreditasi Jurnal Nasional. Diakses tanggal 10 November 2016 dari http://arjuna.ristekdikti.go.id/ index.php/daftarjurnalctl/index/1/

Duranceau, Ellen Finnie (2008). The "Wealth of Networks" and Institutional Repositories: MIT, Dspace, and the Future of the Scholarly Commons. Library Trends, 57 (2), 244-261

Farmer, L. (Ed.). (2007). The human side of reference and information services in academic libraries: adding value in the digital world. Oxford, England: Chandos Publishing.

Haryadi (2014). Ini Alasan Jokowi-JK Ingin Ada Kementerian yang Khusus Urusi Riset dan Teknologi. Diakses tgl. 5 November 2016 dari http://nasional.kompas.com/ $\mathrm{read} / 2014 / 09 / 19 / 22071971 /$ Ini.Alasan. Jokowi-JK.Ingin.Ada.Kementerian.yang. Khusus.Urusi.Riset.dan.Teknologi

Indrawan, Rully (2008). Isi, Format, dan rambu Akrediatsi Jurnal. Diakses tanggal 10 November 2016 dari https://rullyindrawan. wordpress.com/2008/12/02/isi-formatdan-rambu-akreditasi-jurnal/

ISI Research Paper Template. Diakses tanggal 10 November 2016 dari https://docs.google. com/document/d/1Ydr21-YkYeLgE_ qZTLEul-fODs26SqmOi7EBZO8xYkM/edit

Jaguszewski, J., \& Williams, K. (2013). New roles for new times: Transforming liaison roles in research libraries. Diakses tgl. 5 November 2016 dari http://www.arl.org/storage/ documents/publications/nrnt-liaison-rolesrevised.pdf

Johnson, Richard K. (2002). Partnering with Faculty to Enhance Scholarly Communication. D-Lib Magazine 8 (11). Retrieved January 03, 2012 from http://www.dlib.org/dlib/ november02/johnson/11johnson.html

Kementrian Riset, Teknologi dan Pendidikan Tinggi (2016). Jurnal yang Perlu Dipertimbangkan untuk Kenaikan Pangkat/Jabatan Dosen. Diakses tanggal 10 November 2016 dari http://pak.dikti. go.id/portal/?p=41

Kennedy, M. R., \& Brancolini, K. R. (2012). Academic librarian research: a survey of attitudes, involvement, and perceived capabilities. College \& Research Libraries, crl-276.

Kumar, M. (2009). Academic libraries in electronic environment: Paradigm shift. In International Conference on Academic Libraries (ICAL), University of Delhi (North Campus), Delhi, India (pp. 5-8). Diakses tgl. 5 November 2016 dari http:// crl.du.ac.in/ical09/papers/index_files/ical16_182_384_3_RV.pdf

Lembaga Ilmu Pengetahuan Indonesia (2016). Daftar Jurnal Ilmiah Terakreditasi LIPI. Diakses tanggal 10 November 2016 dari 
http://isjd.pdii.lipi.go.id/index.php/DaftarJurnal-Ilmiah-Akreditasi-LIPI.html

Luce, Rick \& Grohsgal, Leah Weinryb (2012). Engaging Research: Libraries in a Shifting Academic Paradigm. World Library and Information Congress 78th IFLA General Conference and Assembly. Helsinki. Diakses tgl. 5 November 2016 dari http:// www.ifla.org/past-wlic/2012/94-luce-en.pdf

Lynch, Clifford A. (2003) Institutional Repositories: Essential Infrastructure for Scholarship in the Digital Age Share Print. ARL: A Bimonthly Report, 226 (Feb 2003), 1-7. Retrieved January 03, 2012 from http://www.arl.org/resources/ pubs/br/br226/br226ir.shtml

Marchionini, G. (1998). Information seeking in electronic environments . Cambridge university press.

McCord, A. (2003). Institutional repositories: Enhancing teaching, learning, and research. EDUCAUSE Evolving Technologies Committee white paper. URL: http://sitemaker. umich. edu/ dams/files/etcom-2003-repositories. pdf [December 4, 2003].

McGovern, N. Y., \& McKay, A. C. (2008). Leveraging short-term opportunities to address long-term obligations: a perspective on institutional repositories and digital preservation programs. Library trends, 57(2), 262-279.

Palmer, Carole L. Lauren C. Teffeau \& Mark P. Newton (2008). Strategies for Institutional Repository Develeopment: A Case Study of Three Evolving Initiatives. Library Trend, $57(2), 142-167$
Pratomo, Gito Yudha (2014). Penggabungan Ristek dan Dikti Dinilai Tepat. Diakses tgl. 5 November 2016 dari http://www.cnnindonesia. com/teknologi/20141027132053-199-8301/ penggabungan-ristek-dan-dikti-dinilai-tepat/

Rice-Lively, M. L., \& Racine, J. D. (1997). The role of academic librarians in the era of information technology. The Journal of Academic Librarianship, 23(1), 31-41.

Siregar, A. R. (2010). Perluasan Peran Perpustakaan Perguruan Tinggi. Diakses tgl. 5 November 2016 dari http://repository.usu. ac.id/bitstream/123456789/16086/1/pusjun2008-(1).pdf

Stamatoplos, A. (2009). The role of academic libraries in mentored undergraduate research: A model of engagement in the academic community. College \& Research Libraries, 70(3), 235-249. Diakses tgl. 5 November 2016 dari http:// dspace.nelson.usf.edu/xmlui/bitstream/ handle / $10806 / 8775 /$ Role $\% 20$ of\% 20 Academic\%20Libraries.pdf;sequence $=1$ 